\title{
Populações Indígenas e as Disposições Consultivas no Sistema Legal Brasileiro: Análise Comparativa das Experiências da Nova Zelândia e da Província de British Columbia no CanadÁ
}

\section{João Daniel Macedo Sá ${ }^{1}$}

\section{INTRODUÇÃO}

O direito internacional incorporou modernos conceitos a respeito da proteção dos direitos humanos, que, inicialmente visavam proteger apenas indivíduos, mas gradualmente e com grande intensidade, começaram a conceber a existência de grupos e direitos coletivos:

A inter-relação entre direitos humanos e proteção ambiental é inegável. Direitos humanos dependem da proteção ambiental, e a proteção ambiental depende do exercício de direitos humanos existentes, como o direito à informação e o direito de participação política² ${ }^{2}$.

Esses direitos devem ser efetivados no plano nacional, e também devem ser estendidos aos povos indígenas.

Entre as comunidades indígenas existe um forte senso de identidade, e uma ligação especial com a terra e o meio ambiente. Isto indica que o setor público deve focalizar maior atenção a questões que envolvem implementação política, fazendo cumprir a legislação ambiental e dando prioridade à defesa dos interesses da sociedade e dos povos indígenas.

O modelo no qual o direito ambiental vem se desenvolvendo está baseado num forte processo de participação pública. Podemos afirmar que grande parte dos países

1 Estudante de Direito, bolsista FIPSE/CAPES - Programa de Direito e Responsabilidade Ambiental (UFPA-BR/Pace University-EUA). Trabalho desenvolvido no curso de Direito Comparado do Professor Dr. Nicholas Robinson.

${ }^{2}$ KISS, Alexandre \& SHELTON, Dinah. International Environmental Law. $3^{\mathrm{a}}$ ed. New York: Transnational Publishers, 2004. p. 726. 
desenvolvidos e dos países em desenvolvimento possui dispositivos legislativos que afirmam esse processo ${ }^{3}$.

O processo de consulta constitui importante ferramenta, que, com o propósito de estabelecer uma política mais transparente, tem sido requerido antes e durante os processos de licenciamento ambiental. ${ }^{4}$

Apesar de estar contido em lei, o processo de consulta continua sendo desrespeitado diariamente. Não se sabe até que ponto a opinião pública deve ser levada em consideração durante os processo de tomada de decisão, e se questiona a legitimidade de um direito que garanta $\mathrm{o}$ acesso do público a essas informações. $\mathrm{O}$ assunto não será abordado neste trabalho, mas um dos objetivos do livre acesso às informações é explicar a lógica em que ocorre a política governamental, além de garantir a lisura do processo de tomada de decisões.

Em relação aos povos indígenas, a realização do processo de consulta constitui requisito importante para a afirmação dos direitos humanos. Esse processo visa a obtenção da autorização das comunidades para o acesso e exploração dos recursos naturais, ou mesmo para definição de atividades relacionadas à política governamental, tanto em suas terra, como em áreas limítrofes.

O direito à informação e o direito à participação política devem ocorrer nos processos diários de tomada de decisão, sempre que esses povos possam ser afetados por planos e ações do governo, tais como o desenvolvimento da agricultura, silvicultura, mineração, geração de energia hidrelétrica, proteção do meio ambiente, construção de infra-estrutura e projetos de assentamento, dentre outros.

Para determinarmos a eficácia do direito ambiental é necessário também que se efetue uma análise do papel delegado aos governos federal, estadual e municipal ${ }^{5}$. Esta diferenciação é importante para que se entenda o poder discricionário desses entes, a fim de que se saiba o papel que cada um pode cumprir.

Este trabalho faz uma análise comparativa sobre o processo de consulta das comunidades indígenas no Brasil, tomando como base o direito internacional e as experiências

3 O Estudo de Impacto Ambiental é um bom exemplo que demonstra a necessidade da participação pública durante os processos de tomada de decisão. Entre os países que adotam esse procedimento de consulta popular estão Brasil, Estados Unidos, Nova Zelândia e quase todos os paises do continente Europeu, dentre outros.

4 O Instituto do Meio Ambiente e dos Recursos Naturais Renováveis (IBAMA), recentemente lançou o Sistema de Informações sobre o Licenciamento Ambiental (SISLIC), que permitirá aos cidadãos o acesso on line aos processos de licenciamento sob avaliação do Ibama, garantindo mais agilidade, qualidade e transparência nos procedimentos. Disponível em: [http://www.ibama.gov.br/novo_ibama/ paginas/materia.php?id_arq=2057]. Acesso em: 17 abril 2005.

5 Neste trabalho, para manter a denominação original utilizada em outros paises, as mesmas entidades também serão referidas como governos nacionais, provinciais ou regionais, e locais. 
nacionais da Nova Zelândia e da Provincia de British Columbia, no Canadá. Foram analisadas também algumas decisões de tribunais que focaram suas atenções a problemas relacionados ao processo de consulta dos povos indígenas.

\section{DIREITO INTERNACIONAL}

Nas últimas décadas os direitos dos povos indígenas motivaram muitas discussões em fóruns internacionais. $O$ resultado desse processo foi um corpo inovador de normas que refletem os anseios dos povos indígenas, e que propõem mudanças nas legislações de cada país.

No fim da década de 70, a agenda internacional de discussão sobre direitos humanos começou a buscar um melhor entendimento sobre as demandas e reivindicações de grupos identificados como "povos indígenas".

A categoria dos "povos indígenas" tem sido entendida como incluindo não apenas tribos, nações ou sociedades nativas das Américas, mas também outros grupos culturalmente diferenciados, tais como os Maoris, na Nova Zelândia, e as chamadas "Primeiras Nações", no Canadá.

O Grupo de Trabalho das Nações Unidas sobre Populações Indígenas define povos indígenas como os "descendentes dos originais habitantes dos territórios desde a colonização por estrangeiros"?

Como conseqüência desse processo, os direitos fundamentais dos povos indígenas ganharam maior reconhecimento do ponto de vista jurídico, e isso tem acontecido, de certa forma, num momento crucial da história, no qual questões ligadas à integridade territorial e soberania nacional têm sido reconsideradas e colocadas em cheque à luz de novos fatos na arena política global ${ }^{8}$.

Em 1989, a Organização Internacional do Trabalho (OIT) aprovou a Convençăo 169 - Sobre os Povos Indígenas e Tribais. A Convenção incentiva os governos a "consultar os povos interessados, mediante procedimentos apropriados e, particularmente, através de suas instituições representativas, cada vez que sejam previstas medidas legislativas ou administrativas suscetiveis de afetá.los diretamente".

${ }^{6}$ Instituto Socioambiental, International Rights. Disponível em: [http://www.socioambiental.org/pib/ english/rights/internat.shtm]. Acesso em: 12 março 2005.

${ }^{7}$ SHELTON, Dina. A Rights-Based Approach to Public Participation and Local Management of Natural Resources, 227, nota de rodapé n. 8. Disponível em: [http://www.iges.or.jp/en/fc/phase1/3ws-26dinah.pdf]. Acesso em: 20 abril 2005.

${ }^{8}$ Instituto Socioambiental, International Rights. Disponivel em: [http://www.socioambiental.org/pib/ english/rights/internat.shtm]. Acesso em: 12 março 2005.

9 Art. $6^{\circ}$, Convenção 169/OrT, de 1989. Disponível em: [http://www.socioambiental.org/pib/portugues/ direito/conv169.shtm]. Acesso em: 10 abril 2005. 
A Convenção 169 também prevê que os direitos dos povos aos recursos naturais existentes nas suas terras deverão ser especialmente protegidos:

Artigo 15, Item 2 - Em caso de pertencer ao Estado a propriedade dos minérios ou dos tecursos existentes nas terras, os governos deverão estabelecer ou manter procedimentos com vistas a consultar os povos interessados, a fim de se determinat se os interesses desses povos seriam prejudicados, e em que medida, antes de se empreender ou autorizar qualquer programa de prospecção ou exploração dos tecursos existentes nas suas terras. Os povos interessados deverão participar sempre que for possível dos benefícios que essas atividades produzam, e receber indenização eqüitativa por qualquer dano que possam sofrer como resultado dessas atividades. (grifo nosso) ${ }^{10}$.

As Nações Unidas desenvolvem um importante papel na defesa dos direitos dos povos indígenas. A Agenda 21 é um dos mais importantes documentos a respeito deste tópico e contém seções específicas sobre os papéis dos governos e dos grupos sociais afetados em estabelecerem um diálogo no processo de tomada de decisões, diálogo esse, que leve em consideração a ligação especial destas comunidades com a terra e com o meio ambiente em que vivem ${ }^{11}$.

A Minuta de Declaração sobre os Direitos dos Povos Indígenas (Comissão de Direitos humanos) é outro importante documento que contém uma série de princípios afirmativos. Apesar da ausência de status legal, a Minuta é considerada fonte do direito intemacional, que tende a comprometer os governos, na medida em que é adotada em consenso pelos países que fazem parte da Organização das Nações Unidas ${ }^{12}$. A Minuta afirma que:

Estados deverão adotar medidas efetivas, em consulta com povos indígenas envolvidos $[\ldots]^{13}$, povos indígenas têm o direito de participarem inteiramente, se assim escolherem, de todos os níveis do processo de tomada de decisão, em questões que possam afetar seus direitos $[\ldots]^{14}$, e o direito de requerer

\footnotetext{
${ }^{10} \mathrm{Id}$.

11 A Agenda 21 foi produzida durante a Conferencia Nações Unidas sobre o Meio Ambiente e Desenvolvimento (UNCED), realizada no Rio de Janeiro, em 1992. O Capitulo 26 afirma que os povos indígenas precisam, "em conformidade com a legislação nacional, de um maior controle sobre suas terras, manejo de seus próprios recursos e participação nas decisões relativas ao desenvolvimento que os afetem, inclusive, quando apropriado, participação no estabelecimento ou manejo de zonas protegidas"(item 4).

Disponível em: [http://www.mma.gov.br/estruturas/agenda21/_arquivos/cap26.doc]. Acesso em: 29 março 2005.

${ }^{12}$ Draft Declaration on the Rights of Indigenous Peoples, E/CN.4/Sub.2/1993/26 (8 de Junho de 1993) (elaborado por Chair-Rapporteur of the Working Group on Indigenous Populations).

13 Art. 16, parte IV.

${ }^{14}$ Art. 19, parte V.
} 
que os Estados obtenham seu prévio consentimento, livre e informado, sobre a aprovação de qualquer projeto afetando suas terras, territórios e outros recursos ${ }^{15}$.

O parágtafo 26, da Declaração de Joanesburgo em Desenvolvimento Sustentável, reafirma o principio numero $10 \mathrm{da}$ Declaração do $\mathbb{R i o}^{16}$, quando reconhece que o "desenvolvimento sustentável requer uma perspectiva a longo termo e com ampla participação baseada em formulações políticas, tomada de decisões e implementação em todos os níveis" ${ }^{\prime \prime}$.

O artigo 27 do Acordo Internacional em Direitos Políticos e Civis tem sido interpretado pelo Comitê de Direitos Humanos das Nações Unidas de uma ampla maneira, para abarcar direitos aos recursos naturais e à terra, afirmando que o gozo desses direitos pode justificar a adoção de medidas legais de proteção e medidas que assegurem a efetiva participação de membros das comunidades minoritárias nas decisões que os afetem ${ }^{18}$.

Ainda assim, pela fragilidade das relações em que o direito internacional subsiste, percebe-se que a proteção dos direitos dos povos indígenas é, em primeira instância, função dos países.

Isto posto, passaremos a discutir a implementação nacional e as provisões consultivas.

\section{BRITISH COLUMBIA}

Confederação de democracia parlamentar, atualmente o Canadá está dividido em 10 províncias e 3 territórios, tendo um sistema legal baseado no direito costumeiro inglês, exceto em Quebec, onde o sistema é baseado no modelo francês, de tradição romana.

A estrutura governamental administrativa é similar à do sistema brasileiro ${ }^{19}$, com os indígenas e as terras reservadas a eles também estando submetidos à exclusiva regulação federal ${ }^{20}$. Os govemos locais são regulados pelas leis das províncias ${ }^{21}$.

${ }^{15}$ Art. 30, parte VI.

${ }^{16} \mathrm{O}$ Principio 10 afirma que: " $A$ melhor maneira de tratar questões ambientais é assegurar a participação, no nivel apropriado, de todos os cidadãos interessados. No nível nacional, cada indivíduo deve Ter acesso adequado a informações relativas ao meio ambiente de que disponham autoridades públicas, inclusive informaçôes sobre materiais e atividades perigosas em suas comunidades, bem como a oportunidade de participar em processos de tomada de decisões. Os Estados devem facilitar e estimular a conscientização e a participação pública, colocando a informaçấo à disposiçâo de todos. Deve ser propiciado acesso efetivo a mecanismos judiciais e administrativos, inclusive no que diz respeito à compensação e reparação de danos."

${ }^{17}$ Disponível em: [http://www.mma.gov.br/estruturas/agenda21/_arquivos/joanesburgo.doc]. Acesso em: 20 marco 2005.

${ }^{18}$ KISS \& SHELTON. op. cit. p. 706. O Art. 27 afirma que "nos Estados em que existirem minorias étnicas, religiosas, e lingüísticas, as pessoas pertencentes a essas minorias não deveram terem negados o direito, em conjunto com os outros membros de seus grupos, de gozar de sua própria cultura, de professar e praticar sua própria religião, ou de falar sua própria língua”.

19 Canadá e Brasil estão baseados num sistema federativo de governo, o que significa que seus governos estão divididos entre autoridades nacionais, estaduais, e locais.

${ }^{20}$ Ato Constitucional de 1985, Seção 91 (24).

${ }^{21}$ Ato Constitucional de 1985, Seção 92 (8). 
No Canadá, o Governo Federal buscou novas alternativas para lidar com os problemas dos povos indígenas e propôs a adoção de uma política voltada para o desenvolvimento sustentável, a ser construída com base num forte processo consultivo ${ }^{22}$. Esta abordagem foi determinada desde o reconhecimento de direitos aborígines pela Constituição e devido à interpretação destes direitos pelas cortes superiores ${ }^{23}$.

A Seção 35(1) ${ }^{24}$, do Ato Constitucional de 1982, reconhece e afirma os direitos aborígines existentes em tratados ratificados pelo o governo e pelos povos indígenas. Desde 1990 tem sido construída uma jurisprudência para a interpretação das garantias dos direitos aborígines. A Suprema Corte do Canadá tem sido questionada quanto à natureza da proteção constitucional conferida pela Seção 35(1) e suas decisões sugerem que o processo de consulta dos povos indígenas é um potencial fator que pode levar ao infringimento desta norma ${ }^{25}$.

Os governos provinciais, locais, e o governo nacional têm fundamental interesse em estabelecer controle sobre o uso do solo, mas a terra é fonte de valores culturais e de subsistência para os índios ${ }^{26}$. Em conseqüência, muitas questões foram trazidas às cortes, desafiando garantias constitucionais e ventilando a possibilidade de o governo poder desconsiderar esses preceitos.

O caso $R$. v. Sparrowe ${ }^{27}$ foi um dos primeiros a requerer dos tribunais uma interpretação acerca do escopo da Seção 35(1), do A to Constitucional de 1982. Em Sparrow, a Suprema Corte indicou que a obrigação fiduciária ${ }^{28}$ existente entra a Coroa e os povos aborígines, em termos de prioridade, requer que, normalmente, os interesses aborígines sejam colocados em primeiro lugar. A justificativa para adoção de entendimento diverso ir á depender "de outras circunstancias inquisitórias", e dentre outras situações, "se o grupo em questão foi consultado em respeito as medidas de conservação propostas e implementadas" 29 .

Em Delgamuukw v. British Columbia ${ }^{30}$, decidido em 1997, a jurisprudência canadense já havia definido uma linha de raciocínio, como foi exposto pela Suprema Corte:

Primeiro, os interesses aborígines nasceram desvinculados da ocupação ou uso especifico da terra, e existiram por um longo e indefinido tempo, anterior à afirmação de soberania.

${ }^{22}$ Indian and Northern Affairs Canada. INAC's Principles of SD. Disponivel em: [http://www.ainc-inac.gc.ca/sd/princ_e.html]...Acesso em: 22 março 2005.

${ }_{23}$ TOTA, Katarzyna B.. Can place-based collaborative planning work between First Nations and Local Governments in Nova Scotia?. Halifax, NS: Dalhousie University, 2002. p. 1.

${ }^{24}$ Constitution Act, 1982. s. 35(1): "The existing aboriginal and treaty rights of the aboriginal peoples of Canada are hereby recognized and affirmed". Disponivel em: [http://laws.justice.gc.ca/en/const/ annex_e.html]. Acesso em: 19 março 2005.

${ }^{25}$ MACKLEM, Patric. Aboriginal Rights and State Obligation. Alberta: Alberta L. Rev, Vol. 36, 1997. p. 112.

${ }^{26}$ TOTA. op. cit. p. 2.

${ }^{27}$ R. v. Sparrow, [1990] 1 S.R.C. 1075 (a partir de agora Sparrow).

${ }^{28}$ Dever fiduciário é a obrigação legal de uma parte em agir nos melhores interesses dé outra parte.

${ }^{29}$ MACKLEM, op. cit. p. 119.

${ }^{30}$ Delgamuukw v. British Columbia, [1997] 3 S.R.C. 1010. (a partir de agora Delgamuukrw). 
Segundo, os interesses aborígines são comuns, consistindo de atividades de subsistência e não proprietárias. Terceiro, no direito comum, os direitos aborígines existem por prazer da Coroa e podem ser extintos quando a intenção desta é clara e evidente. Este poder repousou com a Coroa Imperial durante o período colonial. Com a Confederação, a província obteve titulo à todas as terras da Coroa sujeitas aos "interesses" dos indígenas. Finalmente, a inextinguibilidade dos direitos aborígines não é absoluta. As ações da Coroa e os direitos aborígines podem, em circunstancias próprias, ser reconciliados. Falando de maneira geral, direitos aborígines podem ser regulados pela Coroa apenas quando tal regulação operar para interferir nos direitos aborígines com base em legítimos objetivos da Coroa, que podem honoravelmente ser justificáveis, sem a devida interferência de tais direitos. Além do mais, quando regular, o governo deve ser cuidadoso com o apropriado nível de prioridade que os direitos aborígines têm em relação à competitivas atividades inconsistentes ${ }^{31}$.

$\mathrm{O}$ afastamento de direitos aborígines deve necessariamente estar de acordo com objetivos legislativos que sejam substanciais, tais como o

desenvolvimento da agricultura, silvicultura, mineração, geração de energia hidroelétrica, desenvolvimento econômico dos interiores [...], proteção do meio ambiente e de espécies ameaçadas, construção de infra-estrutura e acomodação de populações externas para suportar esses objetivos ${ }^{32}$.

O caso Delgamuukw demonstra que o dever fiduciário pode ser determinado de uma maneira diferente da idéia de interesse prioritário. A Corte expôs que sempre existe um dever de consulta, mas os direitos aborígines não são absolutos e podem ser afastados pelo governo. A natureza e o escopo do dever de consulta irão variar de acordo com as circunstancias $^{33}, e$, como a Corte bem mencionou, este requisito "pode ser satisfeito pelo envolvimento dos povos aborígines nas decisóes tomadas em respeito às suas terras" ${ }^{34}$.

\footnotetext{
${ }^{31} \mathrm{Id}$.

${ }^{32}$ Id. p. 1111.

${ }^{33}$ Id. p. 1113.

${ }^{34} \mathrm{Id}$.
} 
Acordos contituem sempre melhor solução que litigância. Em conseqüência disto, os governos locais e provinciais procuratam novas alternativas para resolver seus problemas com as comunidades indígenas ${ }^{35}$.

British Columbia é, das províncias canadenses, a que serve de melhor exemplo para ilustrar a peculiar relação estabelecida entre os governos locais e as comunidades originárias da região. Lá, os governos locais estão buscando levar em consideração diversos fatores durante o processo de tomada de decisão. Estes fatores envolvem estudos sobre a viabilidade econômica dos projetos, implicações sociais e culturais, e valores ambientais.

Em British Columbia, o contínuo desenvolvimento e expansão das cidades ocasionou um estreitamento das fronteiras que separam áreas urbanas de terras indígenas. Em conseqüência disso, as relações entre comunidades nativas e não-nativas tornou-se conflituosa. A proximidade das terras indígenas de áreas urbanas densamente povoadas levou os governos locais a estreitarem suas relações com essas comunidades indígenas.

As partes envolvidas definiram metas e passaram a negociar acordos e tratados, com a condição de elevarem a quantidade de terras sob o controle dos índios e de garantir o desenvolvimento econômico da região.

Antes de 1993, a União das Municipalidades de British Columbia (UBCM ${ }^{36}$ não reconhecia o papel dos governos locais na resolução dos conflitos com os índios. Esta reconhecia que haviam apenas três partes envolvidas nos processos de negociação: o Governo do Canadá, o Governo da Província de British Columbia e os Grupos Indígenas. Depois de muita pressão, o governo provincial assinou um Memorando de Entendimento, reconhecendo que os governos locais possuíam especial interesse nas negociações dos tratados, e que não poderiam ser tratados como terceira parte qualquer ${ }^{37}$.

Em 1994, a UMBC e a Província desenvolveram um Protocolo de Entendimento para representar os interesses dos governos locais no processo de negociação dos tratados, reconhecendo objetivos comuns na identificação de todos os interesses que poderiam ser. afetados, e estabeleceu um compreensivo processo de consulta em cada área dos mesmos ${ }^{38}$.

Em 2003, um novo Memorando de Entendimento foi assinado. Este Memorando enfatiza a flexibilidade que os governos locais têm para participar dos processos de negociações dos tratados, e de uma forma adequada às circunstancias da região. $\mathrm{O}$ documento também

${ }^{35}$ Cf. ADAMS, Peter. Approaches and Options for Treaties in Urban area: A Discussion Paper. Prepared for: Union of British Columbia Municipalities, Ministry of Aboriginal Affairs and the Ministry of Municipal Affairs (1999). Disponível em: [http://www.mcaws.gov.bc.ca/lgd/gov_structure/first_nations/ urban.pdf]. Acesso em: 12 março 2005.

36 Union of British Columbia Municipalities.

${ }^{37}$ CivicNet BC. Local Government Involvement In Treaty Negotiations. Disponivel em: [http:// www.civicnet.bc.ca/siteengine/ActivePage.asp?PageID=8\&bhcp=1]. Acesso em: 12 março 2005. ${ }^{38}$ Id. 
propõe diretivas sobre como o compartilhamento de dados e informações irá ocorrer, identificando os papéis e responsabilidades que cada parte deverá desenvolver. ${ }^{39}$

Podemos afirmar que hoje os governos locais estão usando os tratados de uma forma que equilibra os interesses de todas as partes. É um novo processo, que reflete ao mesmo tempo tanto as necessidades dos povos indígenas como da população canadense, e que tenta respeitar o uso tradicional da terra e dos recursos naturais.

\section{NOVA ZELÂNDIA}

O sistema legal da Nova Zelândia está baseado no direito anglo-saxão, e o país possui legislação especial sobre uso da terra e Cortes especiais para os Maoris ${ }^{40}$. Atualmente o país está dividido em 13 regiões e os Atos Constitucionais representam as principais normas na hierarquia legislativa. Alem dos Atos Constitucionais, o país possui outros documentos legais, aprovados tanto pelo Reino Unido como pelo parlamento neozelandês.

Como mencionado, o país possui um tribunal especial, chamado de "Tribunal Waitangi”, que foi estabelecido para julgar reivindicações dos Maoris contra a qualquer ato, política, ação ou omissão da Coroa que pudesse afetá-los de forma prejudicial. Muito embora suas decisões não tenham forca impositiva sobre os atos do governo, o Tribunal se manifesta em muitas questôes, e constitui uma espécie de órgão revisiona ${ }^{41}$.

Antes das reformas administrativas, implementadas durante a década de 1980, as decisões do governo estavam extremamente centralizadas em nível nacional. Este modelo afetava o desempenho e autonomia dos governos locais e regionais, não apenas num âmbito getal, mas também nas questões ambientais ${ }^{42}$.

As discussões da década de oitenta focalizaram-se nesse modelo e levaram à criação de um novo programa de reformas nas esferas administrativa, econômica e social. Na área ambiental, as reformas levaram à reestruturação do governo em nível nacional e impuseram gradativa redefinição da jurisdição dos governos locais e regionais.

${ }^{39} \mathrm{O}$ Memorando também explica como e quando os governos locais podem esperar assistência financeira. Este documento está disponível em: [http://www.mcaws.gov.bc.ca/lgd/gov_structure/first_nations]. Acesso em: 12 março 2005.

40 $\mathrm{O}$ povo Maori representa os originais habitantes da região onde hoje fica a Nova Zelândia. O povoamento do Pacífico ocorreu por meio de inúmeras "ondas" migratórias. Os Polinésios foram os primeiros povos do Pacífico ao Havaí, e ilhas do leste, até a Nova Zelândia, que foi um dos últimos lugares a ser povoado. Quem explica isso é a Pofesso"z Aroha Te Pareake Mead, da Maori Business, Victoria Management School . Victoria University of Wellington, na Nova Zelândia, e que contribuiu para a realização deste trabalho.

${ }^{41}$ O Tribunal Waitangi foi estabelecido pelo Ato sobre o Tratado de Waitangi, em 1975. Cf.: Tribunal Waitangi,disponível em: [http://www.waitangi-tribunal.govt.nz/]. Acesso em: 16 março 2005.

${ }^{42}$ BURTON, Lloyd \& COCKLIN, Chris, Water Resource Management and Environmental policy Reform in New Zealand: Regionalism, Allocation, and Indigenous Relation., Colorado: Colo. J. Int'l Envtl. L. \& Pol'y. - vol. 7, Winter, 1996. p. 85. 
Adotado em 1991, o Ato sobre o Manejo dos Recursos Naturais (RMA) ${ }^{43}$ é uma das mais recentes reformas implementadas na Nova Zelândia. Esta lei reflete a percepção de que deve haver uma descentralização da responsabilidade sobre o manejo dos recursos para os níveis regional e local ${ }^{44}$.

A linguagem do RMA incorpora inúmeros termos da língua Maori, e reconhece a tradicional relação desse povo com a terra, a água e demais recursos naturais. O Ato direciona as autoridades administrativas à especificamente levarem em consideração os princípios constantes no Tratado de Waitangit5.

O Tratado de Waitangi é um documento que foi assinado entre a Coroa Inglesa e os Maoris em 1840 e não possui nenhum status legal independente ${ }^{46}$. Até o presente momento, o tratado é referido separadamente em 35 Atos do Parlamento. A maioria dos estatutos não faz referencia ao Tratado de Waitangi, e os que o fazem, estão relacionados ou com recursos naturais, ou legislação ambiental, ou a leis específicas que tratam dos direitos Maoris. ${ }^{47}$

É importante mencionar que antes do RMA:

a ausência de ratificação formal do Tratado de Waitangi pelo Parlamento encorajava uma linha de análise judicial que sustentava que o governo central da Nova Zelândia e jurisdições subordinadas não deveriam considerar-se legalmente atados ao Tratado, nos processos diários de tomada de decisões, exceto em instâncias em que eles fossem especificamente instruídos pelo Parlamento ${ }^{48}$.

Desse modo, a política governamental foi estabelecida em face do princípio de que os direitos existentes no Tratado de Waitangi não poderiam ser impostos pelos tribunais, exceto quando os mesmos fossem reconhecidos por lei ${ }^{49}$.

Após sua ratificação pelo Parlamento Neozelandês, a segunda parte da Seção 8, do RMA, tornou-se alvo de extensas considerações judiciais, não apenas porque teve o propósito

\footnotetext{
${ }^{43}$ Resource Management Act 1991, 32 R.S.N.Z.

${ }_{44} \mathrm{O}$ RMA define os objetivos para o governo nacional na implementação de padrões nacionais específicos e transfere aos níveis locais e regionais a responsabilidade de implementar o Ato.

${ }^{45}$ RMA, Art. II, $\$ 8$.

${ }^{46} \mathrm{O}$ texto do Tratado de Waitangi está disponível em: [http://www.treatyofwaitangi.govt.nz/treaty/ transiation.php]. Acesso em: 16 março 2005.

47 State Services Commission. The Treaty of Waitangi. Disponível em: [http:// www.treatyo fwaitangi.govt.nz/treaty/principles.php]. Acesso em: 16 março 2005.

${ }^{48}$ BURTON \& COCKLIN. op. cit. p. 93: quando referindo-se à decisão do Conselho sobre o caso Te Heuheu Tukino v. Aotea Dist. Maori Land Bd, [1941] N.Z.L.R. 590 (P.C.), decidido em 1941.

${ }^{49}$ N.Z. Maori Council v. A.G, [1992] 2 N.Z.L.R. 576, 603 (C.A.).
} 
de proteger interesses Maoris, mas também porque este item expressamente reconhece o Tratado de Waitangi. O A to direciona as autoridades locais e regionais a consultarem com os lideres de grupos Maoris sempre que estes possam ser afetados por planos e políticas do governo.

As decisões dos tribunais que se seguiram, focalizaram suas atenções na relação do governo com a população Maori, já que predominantemente, as instituições governamentais nos níveis local e regional, são lidetadas por grupos não-Maoris, e conseqüentemente, estes são os que mais diretamente competem com os Maoris pelos benefícios econômicos da exploração da terra e dos recursos naturais ${ }^{50}$.

Num dos primeiros casos, em Gill v. Rotorua Dist. Council ${ }^{51}$, a Corte foi invocada a decidir se a Seção 8 do RMA ${ }^{52}$ impunha à agencia municipal uma obrigação de consulta quando estivesse licenciando construções residenciais em zonas rurais. $O$ Tribunal julgou que a consulta com o tangata whenua (que literalmente significa 'povo da terra' e é a expressão comumente utilizada para referir-se a comunidade de uma área especifica) era necessária, pois esse era um dos princípios enumerados pelo Tratado de Waitangi. A Seção 8 do RMA impõe ao município uma obrigação de inquirição e não apenas de notificação do tangata whenua.$^{53}$

Em Haddon v. Auckland Resource Council ${ }^{54}$, o Conselho de Recursos Naturais havia recomendado ao Ministro da Conservação que permitisse a extração de areia da costa de North Auckland. Neste caso, a Corte notou que o principio consultivo aparentava não ter sido observado suficientemente antes do término do processo de autorização (licenciamento), dado o interesse Maori pela área. O processo de autorização tem inúmeras fases e a consulta com o tangata whenua tem que ser realizada nos primeiros estágios do processo, para que satisfaça esse principio ${ }^{55}$.

Embora os casos acima citados demonstrem que o RMA explicitamente enfatiza a necessidade do processo de consulta com relevantes grupos Maoris, alguns casos decididos por um diferente juiz, em um posterior Tribunal, levaram a uma conclusão diferente ${ }^{56}$.

Em Hanton v. Auckland City Council ${ }^{57}$, o Tribunal distinguiu entre a explicita obrigação estatutátia de consulta com o tangata whenua, quando os governos regionais e

50 BURTON \& COCKLIN. op. cit. p. 99.

${ }^{31}$ Gill v. Rotorua Dist. Council [1993] 2 N.Z.R.M.A. 604 (P.T.).

${ }_{52}$ Resource Management Act 1991, s. (8): "In achieving the purpose of this Act, all persons exercising functions and powers under it, in relation to managing the use, development, and protection of natural and physical resources, shall take into account the principles of the Treaty of Waitangi (Te Tiritio Waitangi)". Disponível em: [http://www.mfe.govt.nz/laws/rma/]. Acesso em: 18 março 2005.

${ }^{53}$ Gill v. Rotorua Dist. Council [1993] 2 N.Z.R.M.A. 604 (P.T.). p. 616.

${ }_{54}$ Haddon v. Auckland Resource Council [1994] NZRMA 49.

${ }^{55}$ Id.

${ }^{56}$ BURTON \& COCKLIN. op. cit. p. 100.

${ }^{57}$ Hanton v. Auckland City Council [1994] NZRMA 289 (P.T.). 
locais estiverem projetando planos e ações políticas, e a obrigação de consulta nos processos que envolvem a autorização para exploração de recursos naturais, indicando que no segundo caso não existiria uma obrigação explicita.

Em Rural Management Ltd. v. Banks Peninsular Dist. Council ${ }^{58}$, o Tribunal determinou que era obrigação do proponente do projeto, e não da autoridade governamental, identificar possíveis grupos afetados, ainda durante a fase licenciamento, e iniciar um processo de consulta com os mesmos.

Enquanto a abordagem do caso Gill identifica uma obrigação positiva de consulta por parte do Conselho Distrital, interpretação esta também adotada pela Suprema Corte no caso Quarrantine ${ }^{59}$, e que deveria ter sido seguida por outras decisões, a abordagem do caso Hanton indica a imposição de algo menor que uma obrigação consultiva ${ }^{60}$.

O Taratado de Waitangi impõe uma proteção ativa dos interesses Maoris, e o principio da consulta é apenas um dos relevantes aspectos do Tratado $\mathrm{cm}$ face da Seção 8 do RMA. Constata-se que realmente existe um legítimo direito de consulta, e as matérias discutidas ao longo dos últimos anos são inteiramente procedimentais, envolvendo questões tais como prazos e forma de consulta, além da identificação dos grupos que devem ser consultados ${ }^{61}$.

A Nova Zelândia encontra-se num estagio em que a população e o governo reconhecem a importância que o ambiente representa para o povo Maori. O desafio atual é tentar acomodar outros valores, tais como a utilização eficiente dos recursos naturais, de uma maneira que realce e fortaleça o manejo sustentável. Apenas trabalhando em conjunto, essas pessoas poderão obter benefícios mútuos e apaziguar os conflitos.

\section{BRASIL}

O Brasil é um país de tradição romano civilista, e que tem na Constituição da Republica de 1988 seu mais importante documento legislativo. A CF delegou à União competência exclusiva para regular a matéria indígena ${ }^{62}$.

${ }^{58}$ Rural Management Ltd. v. Banks Peninsular Dist. Council [1994] NZRMA 412 (P.T.)

${ }^{59}$ Quarrantine Waste (NZ) Ltd. v. Waste Resources Ltd., [1994] NZRMA 529 (H.C.). Este caso envolveu uma Ação de Revisão Judicial de uma decisão do Conselbo da Cidade de Manukau que autorizava que o processo de licenciamento para uso do solo ocorresse sem consulta.

60 BEVERLEY. op. cit. p. 136. É importante notar que o caso Hanton foi decidido antes do caso Quarrantine.

${ }^{61}$ Id. p. 100.

${ }^{62}$ Art. 22, XIV, CF. O Art. 49, XVI, da CF, atribui ao Congresso Nacional competência exclusiva para autorizar a exploraçäo e o aproveitamento de recursos hídricos e a pesquisa e lavra de riquezas minerais em terras indígenas. 
No Brasil, as condições e o contexto são, de alguma forma, diferentes dos países analisados anteriormente. Segundo as leis brasileiras, os Indígenas etam considerados relativamente incapazes, o que significava que os mesmos possuíam limitações no exercício dos seus direitos civis.

Este princípio foi estabelecido no antigo Código Civil Brasileiro de 1916, sendo adotado ao tempo da promulgação do Estatuto do Índio (Lei Federal n. 6.001/73).

Nós podemos afirmar que o principio da consulta, em alguma instância, ficava diminuído no Brasil, pois as comunidades indígenas eram tutoradas pela Fundação Nacional do Índio (FUNAI), que é um ente estatal. Mas com o advento da Constituição de 1988, a capacidade jurídica dos índios passou a ser rediscutida.

A CF garantiu aos Índios o direito ingressar em juízo na defesa de seus interesses e também delegou expressamente ao Ministério Público Federal (MPF) legitimidade para intervir em defesa dos interesses indígenas ${ }^{63}$.

O Novo Código Civil Brasileiro, de 2002, alterou o artigo que trata do exercício dos direitos civis, e determinou no parágrafo único do Art. $4^{\circ}$, que a capacidade dos índios será regulada por legislação especial. Só que desde àquela época ainda não foi aprovada nenhuma lei sobre o assunto, o que gera ainda mais debate.

Apesar de ter a responsabilidade de proteger e garantir os direitos dos povos indígenas no Brasil, a FUNAI não possui uma especifica obrigação de consulta perante essas comunidades. Teoricamente, não existiria obrigatoriedade de consulta pelo fato de que a legislação especial ainda não foi aprovada, o que deixa a situação dos indígenas pendente. $A$ FUNAI foi criada para proteger os interesses indígenas até que os mesmos fossem integrados à sociedade ${ }^{64}$. Essa realidade não existe mais, e somente com a edição da legislação especial, saberremos como ficará regulamentada essa questão.

Podemos notar que tanto o Canadá quanto a Nova Zelândia possuem dispositivos afirmando que os povos indígenas devem ser consultados de alguma forma, antes ou durante a implementação de projetos que possam causar significativas mudanças nos seus territórios e áreas circunvizinhas.

Analisando essa questão sob outro aspecto, nota-se que no Brasil, também existe um poderoso dispositivo que reflete essa política de proteção dos povos indígenas, e que pode ser interpretado de forma extensiva para limitar a discricionariedade da FUNAI e demais ótgãos que possam exercer competência sobre a matéria. A Magna Carta não apenas

\footnotetext{
${ }^{63}$ Art. 232 c/c Art. $129, \mathrm{~V}, \mathrm{CF}$.

${ }^{64}$ Atualmer te existe um concernimento de que o Estatuto do Índio estaria em violenta divergência aos princípios da $\mathrm{CF}$, pois esta não fala sobre integração nacional das comunidades e, ao contrario, assegura a elas o direito de serem diferentes do resto da nação (Art. 231, CF).
} 
tem um capítulo inteiro dedicado aos Indígenas, como possui um especifico parágrafo, no Art. 231, enfatizando a necessidade de consulta:

$\int 3^{\circ}-$ O aproveitamento dos recursos hídricos, incluídos os potenciais energéticos, a pesquisa e a lavra das riquezas minerais em terras indígenas só podem ser efetivados com autorização do Congresso Nacional, ouvidas as comunidades afetadas, ficando-lhes assegurada participação nos resultados da lavra, na forma da lei. (grifo nosso) ${ }^{65}$.

Em 2001, o Ministério Público Federal (MPF) postulou provimento liminar nos autos da Ação Civil Pública 2001.39.005867-6, objetivando a sustação da elaboração do Estudo de Impacto Ambiental e do Relatório de Impacto Ambiental (EIA/RIMA) para a implantação da Usina Hidrelétrica de Belo Monte, localizada no Rio Xingu, o Estado do Pará $^{66}$.

O MPF sustentou que a $\mathrm{CF}$ requer a autorização do Congtesso Nacional para qualquer projeto intencionado a explorar potenciais energéticos pelo aproveitamento de recursos hídricos em terras indígenas. O MPF desafiou o projeto porque a usina hidrelétrica, caso construída no Riu Xingu, que corta terras indígenas, iria inundar aproximadamente $200 \mathrm{~km}^{2}$ de área, influenciando no volume de água do rio, e afetando as reservas indígenas.

O TRF da $1^{a}$ Região concedeu o provimento liminar, mas o réu requereu efeito suspensivo da decisão para poder permitir a continuidade dos estudos de impacto ambiental para a elaboração do EIA/RIMA e interpôs agravo regimental contra a decisão indeferitória do efeito susperisivo.

A decisão que se seguiu, foi proferida nos seguintes termos:

CONSTITUCIONAL. ADMINISTRATIVO.

PROCESSUAL CIVIL. AÇÃO CIVIL PÚBLICA.

DECISÃO CONCESSIVA DE PROVIMENTOLIMINAR. AGRAVO DE INSTRUMENTO: REEXAME DOS PRESSUPOSTOS DA LIMINAR. AGRAVO REGIMENTAL: NÃO-CABIMENTO. CONSTRUÇÃO DE USINA HIDRELÉTRICA EM RIO DE DOMÍNIO DA UNIÃO E QUE ATRAVESSA ÁREAS DE TERRAS INDÍGENAS. ESTUDO DE IMPACTO AMBIENTAL E RELATÓRIO DE IMPACTO AMBIENTAL. LICENCIAMENTO AMBIENTAL: COMPETÊNCIA DO

\footnotetext{
${ }^{65}$ Art. 231, $₫ 3^{\circ}, \mathrm{CF}$.

${ }^{66}$ Ação Civil Pública n.2001.39.00.005867-6 - 5. Vara Federal - TRF 1ª . Reg - Juiz Silvio Coimbra Mourthe.
} 
IBAMA. DISPENSA DE LICITAÇÃO: REQUISITOS (ART. 24 DA LEI No 8.666/93). APROVEITAMENTO DE RECURSOS HÍDRICOS EM TERRAS INDÍGENAS: NECESSIDADE DE PRÉVIA AUTORIZAÇÃO DO CONGRESSO NACIONAL."

1. Não cabe agravo regimental da decisão que confere ou nega efeito suspensivo em agravo de instrumento (artigo $293, \S 3^{\circ}$, do RI/TRF - $1^{2}$ Região) 2 . O objeto do agravo de instrumento, interposto contra decisão concessiva de provimento liminar, cinge-se ao reexame dos pressupostos para a sua concessão: fumus boni juris e periculum in mora.

3. É imprescindível a intervenção do IBAMA nos licenciamentos e estudos prévios relativos a empreendimentos e atividades com significativo impacto ambiental, de âmbito nacional ou regional, que afetarem terras indígenas ou bem de domínio da União (artigo 10, caput e $₫ 4^{\circ}$, da Lei n ${ }^{\circ} 6.938 / 81$ c/c artigo $4^{\circ}$, I, da Resolução n ${ }^{\circ}$ 237/97 do CONAMA).

4. A dispensa de licitação prevista no artigo 24 , XIII, da Lei $n^{\circ}$ 8.666/93 requer que a contratada detenha inquestionável reputação ético-profissional.

5. O aproveitamento de recursos hídricos em terras indígenas somente pode ser efetivado por meio de prévia autorização do Congresso Nacional, na forma prevista no artigo 231, $₫ 3^{\circ}$, da Constituição Federal. Essa autorização deve anteceder, inclusive, aos estudos de impacto ambiental, sob pena de dispêndios indevicios de recursos públicos.

6. Agravo regimental não-conhecido.

7. Agravo de instrumento a que se nega provimento.

Em seu voto, o Exmo. Str. Juiz Alexandre Vasconcelos sustentou que o aproveitamento de recursos hídricos em terras indígenas somente pode ser efetuado com a

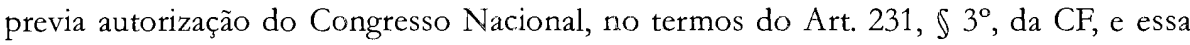
autorização deve anteceder inclusive aos estudos de impacto ambiental, sob pena de dispêndio indevido do dinheiro público ${ }^{67}$.

Como mencionado acima, projetos que podem afetar terras indígenas devem ser licenciados pela agencia ambiental federal, no caso o IBAMA. Atualmente, no Brasil é o proponente do projeto quem deve identificar possíveis comunidades afetadas.

67 Agravo de Instrumento 2001.01.00.030607-5/PA - 6. T.- TRF 1'. Reg- j. 17.09.2001 - rel. convocado Juiz Alexandre Vasconcelos. Voto fls. 5/6. 
Posteriormente, este deve comunicar o IBAMA, que irá contactar a FUNAI. A FUNAI, por sua vez, consulta as comunidades afetadas e emite um parecer ${ }^{68}$.

A Medida Provisória n. 2.186, de 23 de agosto de 2001, que regula o acesso ao patrimônio genético e conhecimento tradicional, também requer o prévio consentimento dos povos indígenas. Este texto legal contém dispositivos que expressamente requerem o prévio consentimento do Congresso Nacional, apos a aprovação das comunidades envolvidas ${ }^{69}$.

A MP 2.186 visa proteger o conhecimento tradicional das comunidades indígenas e locais, e afirma que o governo reconhece os direitos dessas comunidades em decidir sobre o uso desse conhecimento. Isso inclui a realização de testes, pesquisas, ou a exploração ${ }^{70}$. Mais importante é que esse processo de consulta deve ser prévio e informado ${ }^{71}$.

No Brasil, o Governo Federal não autoriza os governos municipais a estabelecerem acordos com os povos indígenas localizados em suas regiões. O motivo dessa restrição parece ser uma preocupação do Governo de que essas entidades careçam de infra-estrutura e treinamento, não estando por isso preparadas para lidar com as comunidades indígenas. Outro fator, ao que nos parece, é o fato de ser o ente municipal o agente responsável pelo micro zoneamento de sua área, podendo por isso, representar o maior perigo aos grupos indígenas. Muitas vezes, é a atuação do Município que determina a distribuição espacial da população, e a exploração dos recursos naturais.

Em 1991 um novo Estatuto do Índio foi proposto, e foi aprovado por uma comissão especial da Câmara dos Deputados em $1994^{72}$. O novo Estatuto adapta a legislação à Constituição de 1988, pois o índio passa a ser apenas assistido pelo Estado. Entretanto, o trâmite deste projeto de lei foi paralisado e até hoje, algumas propostas, inclusive por parte do governo, estão sendo examinadas pelo Congresso, mas não existe nenhuma certeza quanto à aprovação do novo Estatuto das Sociedades Indígenas ${ }^{73}$.

${ }^{68}$ A Coordenação Geral do Patrimônio Indigena e do Meio Ambiente (CGPIMA) é o setor responsável, dentro da FUNAI, pela elaboração dos pareceres. Para maiores informações, disponível em:[http:// www.funai.gov.br/quem/endereco/fone/cgpima2.htm]. Acesso em: 05 abril 2005.

${ }^{69}$ Art. 16, $₫ 9$, MP 2.186.

${ }^{70}$ Arts. $8^{\circ}$ e $9^{\circ}$, MP 2.186.

${ }^{71}$ Art. 11, IV e Art. 14, I, MP 2.186.

72 Projeto de Lei n. 2057/1991, de autoria do à época então, Deputado Aloísio Mercadante-PT/SP.

${ }^{73} \mathrm{Na}$ ultima consulta, datada de 09 de abril de 2005, verificou-se que o Projeto foi encaminhado à Coordenação de Comissões Permanentes (CCP) em 14 de marco de 2005, para republicação, em virtude de incorreções. 


\section{CONSIDERAÇÕES FINAIS}

A observância das normas de direito internacional depende da atuação dos países, pois ainda não existe um efetivo mecanismo que imponha cumprimento das mesmas. No tocante às populações indígenas, não existe nenhum tratado específico, existem apenas acordos. Desse modo, para alcançarmos a proteção desses povos, essa efetivação deve ser estabelecida pelas legislações nacionais de cada país.

Em todos os países analisados, constatamos que existem legislações que incorporam conceitos a respeito da proteção dos direitos dos povos indígenas. Os povos indígenas possuem um direito à terra que lhes é inato, e a realização do processo de consulta reflete a inter-relação dos direitos humanos com a proteção ambiental.

Podemos concluir que o processo de consulta deve ser mais que apenas mera consulta. Deve ser realizado de uma forma efetiva, que não viole os direitos que esses povos herdaram, de viver nesses locais.

Sozinho, o desenvolvimento econômico pode levar a um incontrolado processo de exploração dos recursos naturais. Este sistema deve ser balanceado, baseando-se tanto em políticas de conservação, como na descentralização governamental.

Olhando para o caso de British Columbia, podemos observar que os governos provinciais que negociam em nome dos governos locais podem não endereçar adequadamente as questões sobre o uso do solo e expansão urbana. Podemos também notar que em British Columbia existe um esforço de se cumprir com o processo de consulta, e os governos locais foram chamados à mesa de negociação, e ao menos então tentando estabelecer um processo de diálogo.

Da mesma maneira, na Nova Zelândia, a atual situação em que se encontram os Maoris, e sua participação no processo político de tomada de decisões, reflete uma evolução do conceito. Os Maoris têm sido chamados a efetivamente participarem dos procedimentos de que envolvem a utilização de recursos naturais em suas terras ou áreas de interesse dos mesmos.

Em ambos os casos, o processo histórico levou à realização de acordos entre as comunidades e os governos locais. O papel dos governos nacionais continua sendo o de estabelecer normas nacionais uniformes. E o processo de descentralização tem estendido maior autonomia aos governos locais, que arcam com o ônus de implementar essas políticas.

Por isso, cremos que a inclusão dos povos indígenas e dos governos locais no processo de tomada de decisão do Governo Brasileiro pode melhorar esse sistema, ao mesmo tempo em que possibilitaria o desenvolvimento econômico local e ajudaria a implementar uma política mais eqüitativa.

Sabemos que na maioria das vezes, os poderes locais têtm interesses divergentes aos interesses indígenas, e por isso seria importante que fosse estabelecido um sistema formal e 
bem definido, que permitisse à ambas as partes exporem suas idéias e defenderem seus interesses. Como resultado, seriam produzidos documentos formais vinculativos.

Vale ressaltar que o sistema que o Governo Brasileiro vem adotando para a demarcação das Terras Indígenas é apenas um dos muitos pontos controvertidos que poderia ser trazido às mesas de negociação. Apenas com diálogo será possível evitar o aumento desses conflitos. Do contrário, as áreas indígenas provavelmente continuarão sendo invadidas, e os recursos naturais explorados de forma ilegal, com a aquiescência, ou poderíamos dizer, "condescendência" dos governos locais.

A Constituição Brasileira faz especifica menção ao princípio da consulta dos povos indígenas. Mesmo sendo considerada uma importante provisão, deve ser dito que anterior a autorização do Congresso Nacional, é necessária a consulta das possíveis comunidades afetadas.

O Governo Brasileiro deve rediscutir o papel dos municípios, na busca de estreitar as relações entre os governos locais e os povos indígenas. Poderia ser estabelecido um processo de diálogo, mas essa questão demandará tempo e envolve conflitos de competência. Certo é que essa aproximação poderia levar à concretização de futuros acordos e gerar uma política mais condescendente com o manejo dos recursos.

É importante que se avalie a forma e o grau de consulta com o governo na projeção de planos, políticas e respostas a esses requerimentos de consulta em projetos.

E também é importante que se avalie a capacidade indígena para significativamente entender e participar em procedimentos de licenciamento, dada a complexidade que certos projetos e dado o poder de convencimento dos proponentes em aprovarem os requerimentos. Pode ser difícil para as comunidades para entenderem os impactos que os projetos podem acarretar e isso acaba prejudicando o próprio processo.

O processo de licenciamento ambiental é apenas um dos aspectos que deveria envolver a consulta das comunidades indígenas, pois existem outros fatores. Devemos respeito aos povos indígenas, às suas terras, e aos seus costumes. Se o "branco" não demonstra respeito pelo índio, o índio não tem porque respeitar o "branco". E se o Estado, que é o ente que foi criado para estabelecer as leis e resolver os conflitos em beneficio do bem comum e do povo, não estiver presente, retornaremos ao estado em que o homem buscava o direito pelo exercício de suas próprias razões.

O atual governo parece estar buscando o direito de participação de todos, como podemos perceber pelas palavras da Ministra Marina Silva:

A melhor maneira de tratar questões ambientais é assegurar a participação, no nível apropriado, de todos os cidadãos interessados. No nível nacional, cada indivíduo deve ter acesso adequado a informações relativas ao meio ambiente de que disponham autoridades públicas, inclusive informações sobre 
materiais e atividades perigosas em suas comunidades, bem como a oportunidade de participar em processos de tomada de decisões. Os Estados devem facilitar e estimular a conscientização e a participação pública, colocando a informação à disposição de todos. Deve ser propiciado acesso efe tivo a mecanismos judiciais e administrativos, inclusive no que diz respeito à compensação e reparação de danos ${ }^{74}$.

\section{CONCLUSÕES ARTICULADAS}

1. O processo de consulta está previsto na $\mathrm{CF}$, e é requisito obrigatório, devendo ser estabelecido até mesmo antes da autorização do Congresso nacional.

2. A CF é a lei maior da nação, então o requisito do art. $231, \S 3^{\circ}$, pode ser interpretado de maneira extensiva para obrigar a FUNAI e demais órgãos administrativos a observarem o dispositivo, devendo o processo de consulta ser realizado em todo e qualquer tipo de ação que afete as comunidades indígenas.

3. Constitui alternativa positiva o processo de descentralização política, com gradativo aumento de participação dos governos locais (municípios) no processo de negociação com as comunidades indígenas, principalmente nas áreas onde a distância que separa as terras indígenas dos centros urbanos é cada vez menor.

4. A negociação de tratados entre governos locais e os povos indígenas é uma alternativa viável e tem demonstrado resultados positivos na Nova Zelândia e no Canadá. No Brasil, os tratados podem ser utilizados como alternativa para regiões em que ainda não foram criadas e demarcadas terras indígenas, ou para as regiões que, mesmo com a demarcação, ainda apresentam graves conflitos.

${ }^{74}$ Disponível em: [http://www.mma.gov.br/index.cfm?id_estrutura=18]. Acesso em: 12 abril 2005. 